\title{
Principales diferencias entre la sustitución fideicomisaria portuguesa y la española
}

\author{
Principais diferenças entre a substituição fideicomissária portuguesa e espanhola
}

\section{Main differences between the Portuguese and Spanish trustee substitution}

\section{Pedro Botello Hermosa*}

\section{Resumen}

Existen importantes diferencias entre la sustitución fideicomisaria española y la portuguesa, diferencias que, en mi opinión, permiten afirmar que la institución española es en la actualidad más práctica que la portuguesa, entre otros motivos porque en 2003 fue elegida por el legislador como el instrumento jurídico a través del cual se puede por primera vez vulnerar el principio histórico de la intangibilidad de la legitima española.Palabras claves: Sustitución Fideicomisaria. Portugal. España. Diferencias.

\section{Resumo}

Existem diferenças importantes entre o administrador fiduciário espanhol e português, diferenças que, a meu ver, permitem afirmar que a instituição espanhola é atualmente mais prática que a portuguesa, entre outras razões porque já em 2003 o legislador espanhol introduziu a primeira possibilidade de violação de um dos princípios históricos do direito de herança espanhol, que é a intangibilidade quantitativa da legítima espanhola.

Palavras-chave: Substituição Fideicomissária. Portugal. Espanha. Diferenças.

\section{Abstract}

There are important differences between the Spanish and Portuguese fiduciary trustee, differences that, in my opinion, enable to affirm that the Spanish institution is curretnly more practical than the Portuguese one, among other reasons because back in 2003 the Spanish legislator introduced the first possibility of violating one of the historical principles of Spanish inheritance law which is the quantitative intangibility of the Spanish legitimacy.

Keywords: Fiduciary trustee. Portugal. Spain. Differences.

\section{Introducción}

El presente artículo pretende resaltar las principales diferencias existentes entre la sustitución fideicomisaria portuguesa y la española, pero, ¿qué se entiende por dicha institución?

En Portugal la sustitución fideicomisaria se regula em 11 artículos del Código civil, ${ }^{1}$ concretamente entre los artículos 2.286 y 2.296 , siendo el 2.286 el que la define cuando expone que: "Diz-se substituição fideicomissária, ou fideicomisso, a disposição pela qual o testador impõe ao herdeiro instituído o encargo de conservar a herança, para que ela reverta, por sua morte, a favor de outrem; o herdeiro gravado com o encargo chama-se fiduciário, e fideicomissário o beneficiário da substituição".

Así, la autora Pimenta Coelho (2017, p. 1141) define la institución portuguesa como "una institución anómala en la que hay un heredero que tiene el encargo de conservar los bienes para, a su muerte, revertirlos a otro heredero. Se le da el nombre de fiduciario al heredero gravado con el encargo y fideicomisario al beneficiario de la sustitución".

Doctor por la Universidad de Sevilla. Profesor del Centro San Isidoro, Adscrito a la Universidad Pablo de Olavide de Sevilla. Sevilla - Espanha. E-mail: pedrobh4@gmail.com.

En adelante, C.c. 
Por su parte, Aguiar Branco (2000, p. 25) entiende que se trata de una verdadera sustitución ya que a través de esta "un tercero es llamado a recibir una liberalidad a falta de una primera persona beneficiada o después de ella".

En España la institución se regula en 6 artículos del C.c. español, del 781 al 786, debiéndose entender definida, si bien no lo hace explícitamente, en el 781 cuando recoge que "Las sustituciones fideicomisarias en cuya virtud se encarga al heredero que conserve y transmita a un tercero el todo o parte de la herencia, serán válidas y surtirán efecto siempre que no pasen del segundo grado, o que se hagan en favor de personas que vivan al tiempo del fallecimiento del testador".

Para Traviesas (1927, p. 414), en las sustituciones fideicomisarias el testador designa sucesores suyos en serie, para que todos lo sean efectivamente, unos después de otros, con obligación en el sucesor anterior de conservar y restituir al posterior todos o parte de los bienes hereditarios. El llamado en segundo término recibe la herencia o el legado a través del llamado en primer término, que llega a ser sucesor.

Por tanto, la sustitución fideicomisaria, tanto en un país como en el otro, podría quedar definida como aquella disposición testamentaria en cuya virtud, el testador impone al heredero fiduciario la obligación de conservar y restituir la herencia fideicomitida a los herederos fideicomisarios que fueron designados en testamento.

Toda sustitución fideicomisaria está compuesta por fideicomitente, fiduciario y fideicomisario.

El fideicomitente es la persona que establece en testamento la sustitución fideicomisaria, es decir, el testador.

Fiduciario es el que sucede al testador en primer lugar, por ello, a diferencia de algunos autores que entienden que podría definirse como heredero intermedio, particularmente considero más correcto el término primer heredero, ya que éste ${ }^{2}$ será el encargado de restituir por primera vez la herencia fideicomitida al fideicomisario una vez se cumpla la condición o se alcance el término fijado por el testador (LASARTE, 2011, p. 127).

El fiduciario es considerado el primer heredero del testador, lo que significa que es el propietario de los bienes fideicomitidos sujetos a sustitución, si bien lo es con carácter temporal (hasta que llegue el plazo fijado para la restitución) o condicional (hasta que se cumpla la condición fijada para que se produzca la sustitución), pero propietario al fin y al cabo.

Por su parte, fideicomisario es el que recibe el patrimonio fideicomitido del fiduciario, por lo que podríamos referirnos a éste como heredero final, sobre el que no pesará ninguna carga de conservación y restitución, a no ser que el testador-fideicomitente haya dispuesto otra cosa. ${ }^{3}$

El fideicomisario es tan heredero del fideicomitente como el fiduciario, ${ }^{4}$ ya que, al establecer una sustitución fideicomisaria, lo que pretende el testador es instituir más de un heredero con su herencia, concretamente, uno después de otro, o lo que es lo mismo, que la intención del testador a través de la institución es que primero herede el fiduciario, para hacerlo posteriormente, una vez llegado el término o cumplida la condición, el fideicomisario.

\section{Posibilidad de usar el término fideicomiso en Portugal, y no en España}

Mientras que el Código civil ${ }^{5}$ español hace referencia a la institución como sustitución fideicomisaria, el C.c. portugués se refiere a ella como sustitución fideicomisaria o fideicomiso, cuando comienza exponiendo el artículo 2.286 que "Dícese sustitución fideicomisaria, o fideicomiso, a la disposición por la cual el testador impone al heredero....".

O sus herederos, en el caso normal de que la sustitución fideicomisaria se establezca hasta la muerte del fiduciario.

Puede ocurrir que el fideicomitente haya establecido que al primer fideicomisario le suceda otro, en cuyo caso, el fideicomisario actuaría como fiduciario de la herencia fideicomitida, por lo que ya no sería el heredero final sino que podríamos definirlo como un heredero intermedio que tiene que conservar y restituir los bienes fideicomitidos, y así sucesivamente hasta el nombramiento del heredero final.

4 Es decir, que el fideicomisario heredará siempre al fideicomitente, y nunca al fiduciario, aunque sea éste el que le haga entrega de los bienes cuando llegue el momento oportuno.

En adelante C.C. 
Bajo mi punto de vista, el hecho de usar como sinónimos ambos términos, "fideicomiso"y "sustitución fideicomisaria", carece de sentido y produce una confusión terminológica respecto a dos figuras jurídicas completamente distintas, tal y como ya expuse en un artículo dedicado exclusivamente a esta cuestión (BOTELLO HERMOSA, 2016).

En la misma línea también se encuentra algún autor portugués, como Da Cunha Gonçalves (1935, p. 146), cuando expone que el fideicomiso "designa más correctamente la herencia o legado sobre el cual se realiza el reemplazo".

Dicho lo cual he de reconocer que aunque el C.c. español no menciona la figura del fideicomiso, sí que es cierto que a día de hoy, gran parte de la doctrina y jurisprudencia española a la hora de hacer referencia a la sustitución fideicomisaria lo sigue haciendo con el término "fideicomiso".

En este sentido, Puig Ferriol (1965, p. 24-25) argumenta que

[...] durante mucho tiempo, fideicomiso y sustitución fideicomisaria fueron tratados como si formaran una sola institución, sin reparar en que respondian a dos concepciones y a dos épocas distintas. Ello tenía sus inconvenientes, pues se pretendía explicar con materiales sacados del Derecho romano primitivo situaciones que obedecían únicamente a peculiaridades propias de este Derecho, con lo cual aumentaban las confusiones en una materia ya de por sí difícil. En los últimos tiempos, los tratadistas procuraron poner de relieve las diferencias existentes entre una y otra figura".

Efectivamente, no son pocos los autores que se encargaron de exponer las diferencias entre una y otra institución.

Así, por ejemplo, Castán (1942, p. 441) reconoce que

la dualidad de herederos diferencia la sustitución fideicomisaria del fideicomiso romano. En la primera el fiduciario es realmente heredero y disfruta, como tal, de la herencia, mientras que en el segundo el fiduciario aparece como un mero mandatario o ejecutor testamentario, encargado de entregar los bienes al verdadero heredero. En la sustitución fideicomisaria hay, por consiguiente, dos o más liberalidades; en el fideicomiso una sola liberalidad...La distinción entre el fideicomiso y la sustitución fideicomisaria resulta reconocida y confirmada por la jurisprudencia.

Por su parte, Jerónimo López (1955, p. 452) expone:

extrañará que los autores antiguos se refieran indistintamente al fideicomiso (de residuo o no) y a la sustitución fideicomisaria (de residuo o normal), porque en la actualidad (a partir de la formación de los Códigos civiles) se diferencian netamente los conceptos de fideicomiso y de sustitución fideicomisaria, y se establece una diferencia tajante entre ambos. En el fideicomiso, institución propia del Derecho romano, un heredero (fiduciario) está obligado a transmitir los bienes al fideicomisario, que no lo es; en la sustitución fideicomisaria moderna se establecen, en cambio, dos o más liberalidades a favor de personas llamadas como herederos en orden sucesivo, lo que significa la superación del principio romano semel heres, semper heres. De esta diferencia de configuración se derivan consecuencias importantes.

De Buen (1975, p. 452) expone que:

El rigor conceptual obliga a lamentar la lastimosa confusión de dos figuras del Derecho sucesorio, que, como el fideicomiso y la substitución fideicomisaria, son, en sí, completamente diferentes y que, por lo mismo, debieran recibir (y reciben) un trato jurídico distinto. (...) Dejando aparte cuestiones de léxico, que tienen, sin embargo, su importancia, lo cierto es que, según queda expuesto más atrás, ninguna de las notas que caracterizan a la substitución fideicomisaria, se dan en el fideicomiso. (...) Las notas diferenciales, pues, resaltan de tal modo, que la confusión -a efectos dogmáticos- está injustificada por completo.

En el mismo sentido se expresa Sánchez Román (1910, p. 691) cuando argumenta:

[...] tratamos únicamente de recordar los conceptos fundamentales que han de servirnos para apreciar en su verdadero valor las disposiciones del Código y para evitar confusiones en que, dada la complicación de la materia, sería fácil incurrir como han incurrido ilustrados tratadistas. Así el Sr. Falcón, al tratar de ella encabeza su explicación con el epígrafe: Sustituciones fideicomisarias o fideicomisos. (...) 
Con lo que antes se ha dicho basta para comprender que no es enteramente exacto lo que afirma el Sr. Falcón, y que se equivoca al confundir dos instituciones que presentan distintos caracteres.

Y la autora Solé resina (2011, p. 972), por su parte, considera

importante distinguir ya de inicio el fideicomiso de la sustitución fideicomisaria. En el fideicomiso, el primer llamado ha de hacer entrega de los bienes fideicomitidos de una manera inmediata; mientras que en la restitución fideicomisaria, la restitución tiene lugar después de un tiempo (cuando llega el término o se cumple la condición impuesta), de modo que hasta este momento el fiduciario conserva los bienes y los tiene en su dominio.

Igualmente, el Tribunal Supremo español no duda en considerar diferentes ambas instituciones, como refleja, por ejemplo, en su Sentencia de 11 de enero de $1996,{ }^{6}$ donde establece que:
Las diferencias más notorias entre ambas instituciones son:
a.- En el fideicomiso puro hay una sola liberalidad, pues el testador contempla y dispone a favor de una sola persona o de varias a la vez, en cambio en la sustitución fideicomisaria, existen al menos dos actos de liberalidad, uno a favor del heredero fiduciario y otro a favor de los herederos fideicomisarios, existe, pues, una sucesión en la herencia, es decir, dos o más liberalidades, cosa que no ocurre en el fideicomiso.
b.- En el fideicomiso el fiduciario no es heredero, sino "ejecutor testamentario", en la medida en que el testador le encarga sobre la base de la confianza la entrega de la herencia al heredero, en cambio en la sustitución fideicomisaria el fiduciario es heredero.
c.- En el fideicomiso existe un encargo o ruego del testador al fiduciario acerca de que cumpla su voluntad, en cambio en la sustitución fideicomisaria existe para el fiduciario una obligación jurídica de conservar y transmitir los bienes de la herencia a los herederos fideicomisarios.
d.- En el Derecho civil común se regula la sustitución fideicomisaria, pero no el fideicomiso.

Leyendo la opinión de estos autores y la línea marcada por el Tribunal Supremo español, parece de obligado cumplimiento cuestionarse: ¿pero entonces, por qué se confunden ambas instituciones en España y en Portugal?

Vayamos por partes.

Es sabido que en el Derecho antiguo de Roma sólo podían recibir liberalidades mortis causa aquellas personas que gozasen de la testamentifactio, por lo que todo aquél que careciese de la misma quedaba incapacitado para heredar.

Dentro de dichos grupos de personas incapacitadas para heredar destacaban los extranjeros o peregrini, los desterrados o proscritos (víctimas de las guerras civiles), así como las personas inciertas, los póstumos, e incluso las mujeres romanas en ciertos supuestos (limitaciones que introdujo la Lex Voconia, 167 a.C.).

Cuenta Costa (1905, p. 7-8) que para eludir el rigor del Derecho Civil de la época en cuanto a la imposibilidad de heredar por parte de todas estas personas que no gozaban de testamentifactio, se ideó un medio indirecto: disponer a favor de una persona capaz y rogarle en el testamento, o bien reservadamente, de palabra o por escritos privados, que restituyese la herencia o el legado a la persona incapaz que el testador le designaba.

En la misma línea, De Abreu Lima (1950, p. 33) considera que esta figura era una forma de "defraudar la ley" porque el Derecho Romano prohibía la disposición de los bienes a favor de ciertas personas, como los incapaces o los extranjeros, que era precisamente lo que se conseguía a través de los fideicomisos.

Era una liberalidad indirecta, confiada al honor y a la buena fe del instituido y dependiente por entero de su voluntad, no de la ley, de donde vino el llamarse fideicomisos (derivado del término latino fideicommisum, compuesto por las palabras fides: "compromiso solemne", "juramento"; y commisum: "encargo", "cosa confiada")

En tal sentido Santos Justo (2009, p. 260) expone que el fideicomiso se traducía como "la súplica o el encargo que una persona (fideicomitente), confiando en la lealtad y honradez de otra persona (fiducario) le

6 RJ 1996, 4271. 
dirigía para que realizase una determinada actividad a favor de una tercera persona (fideicomisario) después de la muerte del fideicomitente".

El fiduciario en el fideicomiso no disfrutaba de la herencia fideicomitida, sino que simplemente se limitaba a cumplir con el encargo del testador, transmitiendo de forma inmediata los bienes fideicomitidos a la persona que carecía de capacidad para heredar por sí misma.

Por ello, podemos definir el fideicomiso como el encargo mediante el cual una persona encomendaba a la lealtad y conciencia de otra, el cumplimiento inmediato a la muerte del primero de una serie de disposiciones patrimoniales a favor de un tercero, surgiendo, pues, como un simple ruego aislado totalmente del rigor del Derecho Civil, pero apoyado en la fides, ${ }^{7}$ que era uno de los rasgos esenciales del carácter nacional de la época.

Por su parte, la sustitución fideicomisaria es la disposición testamentaria en cuya virtud el testador concede al heredero fiduciario el derecho a disfrutar de la herencia fideicomitida como propietario, si bien al mismo tiempo le impone la obligación de conservar y restituir la herencia fideicomitida a los herederos fideicomisarios ya designados en testamento.

Por tanto se puede afirmar que el fideicomiso y la sustitución fideicomisaria tienen finalidades distintas, si bien la confusión entre ambas instituciones puede deberse a que el origen de la sustitución fideicomisaria se encuentra precisamente en una modalidad del fideicomiso romano llamado fideicommissum familiae relictum o fideicomiso familiar romano.

Así lo reconoce en Portugal Santos Justo (2009, p. 264-265), mientras que en España, entre otros, Ossorio Morales (1957, p. 266) considera que "la sustitución fideicomisaria tiene su antecedente en el fideicomiso romano, y especialmente en una modalidad de éste, el fideicommissun familiae relictum".

Ya en el siglo II d. C., por parte de los padres era general el deseo de evitar la disolución de los patrimonios que se disipaban en manos de los hijos, por lo que surgió la idea de prohibir la enajenación de los bienes a fin de conservarlos en la familia para siempre.

Para ello surgió el fideicommissum familiae relictum, a través del cual, el testador podía vincular la herencia, íntegra o parcialmente, a la familia mediante un orden sucesivo de restituciones, quedando privada a los beneficiarios la facultad de enajenar.

Mediante el fideicomiso familiar el causante podía ordenar al fiduciario que tras disfrutar éste de la herencia por un periodo de tiempo (por regla general hasta su muerte), lo restituyese a favor de una persona determinada, o igualmente podía establecer que directamente fuese el beneficiario el que eligiese al próximo heredero, o incluso, podía el testador ordenar el fideicomiso a favor de todos los miembros de la familia, por lo que habrá de estarse a lo que se entendía por familia. En la época de Justiniano, el término familia englobaba tanto a los ascendientes, descendientes y parientes, como al yerno y a la nuera a falta de éstos, $\mathrm{y}$, en último lugar, a los libertos.

Pero la esencia del fideicomiso de familia era, sin lugar a dudas, la prohibición de enajenar los bienes objeto de la herencia, lo cual suponía que el patrimonio del testador iría pasando de unas manos a otras dentro siempre de su familia.

Por ello se entiende que el fideicomiso familiar romano, origen de nuestra sustitución fideicomisaria, y el fideicomiso romano no son la misma institución. Así, por ejemplo, lo reconoce Castán (1942, p. 247), cuando cuenta que

[...] el Senado-Consulto Pegasiano llegó a exigir la misma capacidad para ser fideicomisario que para ser heredero. Y con ello quedaron casi anulados la utilidad y fines de la institución. Pero como una variedad del fideicomiso, apareció en la misma Roma otra institución que respondía a fines muy distintos, $y$ ha sido el germen de las modernas instituciones fideicomisarias: nos referimos al fideicomiso

La Fides en el sistema del Derecho romano era la lealtad en el cumplimiento de lo prometido, la conciencia del deber de corresponder la confianza que otro depositaba en uno, en definitiva, el respeto a la palabra, al entregarse a su lealtad como hombre honrado, siendo de una importancia tal para los romanos que aun estando el fideicomiso falto de sanción jurídica y de propia obligatoriedad, el encargo se cumplía en la gran mayoría de supuestos. 
sucesivo gradual o familiar (fideicommissum familiae relictum), por medio del cual el testador hacía varios llamamientos para la restitución sucesiva de los bienes o prohibía la enajenación de los mismos con objeto de que se conservaran en los individuos de una familia determinada.

O en la misma línea Puig Brutau (1977, p. 525), que considera que

[...] el fideicomiso perdió su utilidad en Roma cuando el Senado Consulto Pegasiano exigió la misma capacidad para ser fideicomisario que para ser heredero. Pero entonces empezó la evolución que ha conducido a que se distinga claramente el fideicomiso puro de la sustitución fideicomisaria. La estructura del fideicomiso romano permaneció al servicio de una función diferente: la que permitía al causante vincular su herencia a una trayectoria predeterminada, de manera que fueran titulares de sus bienes varias personas sucesivamente. Combinándose las ideas de sustitución y fideicomiso, se disponía que éste favoreciera ante todo al heredero instituido en primer lugar, y después, transcurrido cierto plazo o cumplida una condición (generalmente, fallecido el primer instituido), que los bienes del fideicomiso pasaran a un segundo instituido. Es a lo que se llamó substitutio fideicomissaria, origen del fideicomissum familiae relictum, del que deriva la moderna sustitución fideicomisaria.

De hecho entre el fideicomiso romano y el fideicomiso familiar romano se aprecian, entre otras, las siguientes diferencias:

- El fideicomiso familiar romano obligaba al fiduciario a conservar los bienes fideicomitidos hasta su muerte, o hasta que se cumpla la condición fijada por el testador; mientras que a través del fideicomiso romano, la transmisión o restitución de los bienes debía producirse de manera inmediata, o en un plazo muy breve de tiempo, a favor de la persona que carecía de testamentifactio.

- Otra diferencia la encontramos en el hecho de que el fideicomiso familiar romano conlleva la inalienabilidad de los bienes y un orden preestablecido de suceder, cosa que no sucede en el fideicomiso romano.

En definitiva, el único motivo por el cual considero que la sustitución fideicomisaria puede llegar a confundirse con el fideicomiso es precisamente que dicha institución tiene su origen en un tipo de fideicomiso, el llamado fideicomissum familiae relictum, si bien bastará simplemente atender a la definición de una y otra institución para llegar a la conclusión de que la sustitución fideicomisaria y el fideicomiso son dos figuras completamente diferentes que no deben, ni tienen, por qué confundirse.

\section{La opción de un único llamamiento en Portugal, y del doble llamamiento en España}

Tanto en España como en Portugal serán válidas todas las sustituciones fideicomisarias, sin limitación alguna, siempre y cuando todos los llamados vivan al momento de morir el causante.

Así se desprende del artículo 2.287 del Código portugués, cuando afirma que "puede haber uno solo o varios fiduciarios, así como uno o varios fideicomisarios", mientras que en el Código español es el artículo 781 el que expresa que serán válidas y surtirán efecto las sustituciones fideicomisarias "que se hagan a favor de personas que vivan al tiempo del fallecimiento del testador".

Y es que, tal y como exponen Díez-Picazo y Gullón (2012, p. 98), los llamamientos sucesivos a favor de personas que viven al tiempo del fallecimiento del testador no presentan ninguna dificultad, porque la simultaneidad de sus vidas significa que la vinculación de los bienes afectados por la sustitución no va a prolongarse demasiado en el tiempo.

Por tanto, no existe límite alguno por parte del testador a la hora de nombrar posibles fiduciarios y fideicomisarios, siempre y cuando éstos vivan al fallecimiento del causante.

Sin embargo, la diferencia entre ambos ordenamientos jurídicos se presenta en cuanto al número de llamamiento de personas que no viven al fallecer el testador, ya que mientras en Portugal el artículo 2288 de su C.c. fija que "son nulas las sustituciones fideicomisarias en más de un grado", el C.c. español recoge en su artículo 781 que serán válidas y surtirán efectos las sustituciones fideicomisarias "siempre que no pasen del segundo grado". 
Cuando los referidos Códigos hablan de "grados" hacen referencia a "llamamientos", entendiéndose siempre que el primer llamamiento es el que el testador hace a favor del primer fideicomisario (ya que el fiduciario no es un sustituto, sino el instituido como heredero). En tal sentido expone Ossorio Morales (1957, p. 289) que "existe hoy perfecto acuerdo en que para contar los grados permitidos en la sustitución fideicomisaria hay que excluir al primer llamado (o sea al fiduciario), de suerte que puede haber después de él dos sustitutos o fideicomisarios sucesivos"; mientras que los autores Díez-Picazo y Gullón (2012, p. 98-99) también razonan "la llamada al fiduciario no agota ningún llamamiento, porque el art. 781, en esa interpretación, lo que permite son dos sustitutos, y el fiduciario no es más que un instituido, no un sustituto. Sustitutos suyos son los llamados sucesivamente para el momento que tenga que restituir la herencia."

Por todo ello, en Portugal como máximo podemos encontrarnos con sustituciones fideicomisarias en la que aparecen un fiduciario y un único llamamiento a favor de un fideicomisario, mientras que en España podríamos encontrarnos con la institución de un fiduciario y el llamamiento posterior de otros dos fideicomisarios.

En tal sentido expresa la autora Pimenta Coelho (2017, p. 1143) respecto al único llamamiento posible en Portugal que "La regla relativa a los fideicomisos es la de que apenas pueden tener un grado (...). No puede as el autor de la sustitución dejar los bienes a B para, que a su muerte, pasaran a C, y por muerte de C, pasaren a D".

Precisamente el supuesto que expone la autora portuguesa como prohibitivo en Portugal por exceder de un Ilamamiento, sí que tendría cabida en España donde son posibles los dos llamamientos.

Por último, entiendo oportuno resaltar que ambos ordenamientos jurídicos sí coinciden en entender nulos los llamamientos que excedan de los límites fijados en sus respectivos Códigos civiles, si bien dicha nulidad no comporta la de los llamamientos permitidos (fiduciario, primer fideicomisario y segundo fideicomisario en España, y fiduciario y primer fideicomisario en Portugal), al no perjudicar en nada los llamamientos permitidos la validez de la institución, tal como se recoge en el artículo 2289 portugués

"A nulidade da substituição fideicomissária não envolve a nulidade da instituição ou da substituição anterior; apenas se tem por não escrita a cláusula fideicomissária, salvo se o contrário resultar do testamento", y en el 786 español "La nulidad de la sustitución fideicomisaria no perjudicará a la validez de la institución ni a los herederos del primer llamamiento; sólo se tendrá por no escrita la cláusula fideicomisaria".

Al respecto Pimenta Coelho (2017, p. 1143) expone que

El hecho de haber más de un grado en el fideicomiso no acarrea la nulidad de toda la institución. Si por ejemplo, el de cuis deja los bienes a B para que por muerte de B, reviertan a $\mathrm{C}$, y por muerte de este, sean retribuidos a $D$, el primer grado de sustitución es considerado válido, y se tiene por no escrita la segunda sustitución.

\section{El limitadísimo alcance de la sustitución fideicomisaria de residuo en Portugal en comparación España}

En España la sustitución fideicomisaria de residuo es la disposición de última voluntad del testador, a través de la cual, y a diferencia de lo que ocurre con la sustitución fideicomisaria ordinaria, se permite al fiduciario disponer de todos o parte de los bienes fideicomitidos, de modo que el fideicomisario adquirirá en el momento de la restitución los bienes de los cuales el fiduciario no haya dispuesto, y en caso de haber dispuesto de todos, se quedará el fideicomisario sin adquirir ninguno.

O dicho de otro modo, a través de la sustitución fideicomisaria de residuo, el fideicomisario sólo tendrá derecho a los bienes fideicomitidos de los que el fiduciario no haya dispuesto "inter vivos", o incluso, "mortis causa", de haberlo autorizado así expresamente el testador.

Lo cierto es que en el ordenamiento jurídico español, tal y como comenta Lasarte $(2011$, p. 136), pese a su denominación, la sustitución fideicomisaria de residuo es más frecuente, en la realidad, que la 
sustitución fideicomisaria ordinaria. Así se deduce de la jurisprudencia al respecto y así lo afirman la mayor parte de los notarios, buenos conocedores por antonomasia de la práctica sucesoria.

Valga, pues, la paradoja: la sustitución fideicomisaria de residuo no puede ser considerada una figura residual en la práctica testamentaria, al menos, si se la compara con la sustitución fideicomisaria ordinaria. Y es que, tal y como recientemente expuso Rivas Martínez (2014, p. 487), "esta figura (refiriéndose a la institución de residuo), es, sin ningún género de dudas, la que está llamada a tener un mayor desarrollo, y podrá resolver el sinnúmero de problemas que puedan plantearse en la práctica profesional".

En cuanto a la facultad del fiduciario a la hora de disponer de los bienes fideicomitidos, coinciden la doctrina y la jurisprudencia española al afirmar que puede ser muy variado el grado de permisividad mostrado por el testador.

Así, por ejemplo, podría el fideicomitente conceder al fiduciario la facultad únicamente de consumirlos, o también de enajenarlos ( $y$ esto a título oneroso o a título gratuito sin más), o bien de disponer de algunos en concretos, o de disponer de todos, etc.

Dicho lo anterior, hemos de reflejar que tal y como argumenta Díaz Alabart (1981, p. 231), el fin que habitualmente se persigue con la sustitución fideicomisaria de residuo es la concesión de la facultad de enajenar inter vivos en los casos que lo necesite el fiduciario; aunque suele establecerse que dicha necesidad quede a juicio del mismo, y que no tenga deber de justificarla.

En el mismo sentido, expone la autora Nieto Alonso (2014, p. 34) que cualquier estudioso mínimamente avezado de estas instituciones testamentarias, puede constatar que las modalidades más habituales en estas figuras jurídicas en las que el testador dota a los favorecidos con facultades dispositivas, son las que subordinan esta disposición a la situación de necesidad, sea del fiduciario o del usufructuario.

Eso sí, no se podrá estimar que existe facultad de disponer de bienes fideicomitidos sino cuando conste que se concedió expresamente, debiendo estimarse que dicha facultad de disposición únicamente se extiende a los casos para los que conste que se autorizó.

Una vez expuesto lo anterior, hemos de afirmar que las dos clases de sustituciones fideicomisarias de residuo que existen en España emanan del grado de permisividad que el testador tenga con el fiduciario, y que según la jurisprudencia de nuestro Tribunal Supremo, ${ }^{8}$ se clasifican en sustituciones fideicomisarias si aliquid supererit (si queda algo) y de eo quod supererit (de aquello que debe quedar).

En las sustituciones fideicomisarias de residuo de eo quod supererit (de aquello que debe quedar), el fiduciario contará con facultades de disposición inter vivos sobre ciertos bienes fideicomitidos, pero no sobre todos, ya que la intención del testador es que una vez llegado el término o cumplida la condición, ciertos bienes vayan a parar al fideicomisario.

Dicho de otra forma, el fiduciario, en esta modalidad, no podrá disponer libremente de toda la herencia fideicomitida, por ser voluntad del fideicomitente que el fideicomisario reciba parte de la herencia, por pequeña que ésta sea.

En cambio, en los supuestos de sustituciones fideicomisarias si aliquid supererit (si queda algo), nos encontramos en aquellos casos en los que el testador faculta al fiduciario a disponer inter vivos de todos los bienes fideicomitidos, sin ningún tipo de límite, es decir, que el fiduciario podrá disponer absolutamente

Así lo refleja, entre otras, la Sentencia del Tribunal Supremo de 7 de enero de 1.959, al exponer que "...el fideicomiso de residuo puede adoptar dos modalidades: 1. ${ }^{a}$ Hipótesis en que el testador faculte al fiduciario para disponer de los bienes objeto de la institución sin trabas de ningún género. En este caso los herederos fideicomisarios sólo recibirán, en su día, lo que quede o reste, si algo efectivamente queda de la herencia. (En esta hipótesis aparecerá el fideicomiso conocido como si aliquid supererit, si queda algo).

$2^{a}$. Supuesto en la que el causante restringe al fiduciario los poderes de disposición de tal forma que siempre los fideicomisarios deben recibir un mínimo del caudal hereditario, que necesariamente ha de recaer en ellos, por expresa voluntad de aquél (aparecerá el llamado de eo quod supererit, de aquello que deba quedar)".O, también, la Sentencia de 25 de mayo de 1.971, mediante la cual, reitera que "en cuanto a la naturaleza de las cláusulas testamentarias de residuo, depende sobre todo de la intención del testador, pudiendo adoptar dos modalidades: Primera. En el supuesto de que el testador (fideicomitente) faculte al fiduciario para disponer de los bienes objeto de la institución sin trabas de ningún género, en cuyo caso los herederos fideicomisarios sólo recibirán en su día lo que quede o reste (si aliquid supererit), si queda algo; y Segunda. En la hipótesis de que el causante restrinja los poderes de disposición de tal forma que siempre los fideicomisarios deben recibir un mínimo del caudal hereditario, que necesariamente ha de recaer en ellos por expresa voluntad de aquél (de eo quod supererit), de aquello que debe quedar". 
de toda la herencia fideicomitida, por lo que los fideicomisarios sólo recibirán llegado el momento oportuno, lo que queda de la herencia fideicomitida, si es que queda algo, y de ahí la expresión de "si queda algo".

Una vez expuesto el alcance de la institución española toca preguntarse: ¿en qué consiste la sustitución fideicomisaria de residuo portuguesa?

En Portugal existe un tipo de sustitución fideicomisaria de residuo mucho más restringida que la española, ya que el C.c. portugués la recoge en las sustituciones fideicomisarias irregulares, concretamente en su artículo 2.295.1.b), que establece que las disposiciones por las cuales el testador llame a alguien a heredar lo que quede a la muerte del heredero son tenidas como sustituciones fideicomisarias, si bien en el .3 del mismo artículo fija que en los casos del 2.295.1.b), el fiduciario podrá disponer de los bienes por actos entre vivos, con independencia de la autorización judicial, si obtiene el consentimiento del fideicomisario.

O lo que es lo mismo, en la sustitución fideicomisaria de residuo portuguesa, el fiduciario dispone del consentimiento del fideicomisario para poder disponer de los bienes fideicomitidos, lo cual restringe enormemente (por no decir completamente) la facultad de disponer del fiduciario, ya que parece difícil imaginar qué fideicomisario va a permitir al fiduciario que venda los bienes que en un futuro podrían ser suyos.

En tal sentido, se afirma en la sentencia del Tribunal de Apelación de Coimbra 01/17/2017 ${ }^{9}$ que:

I.- Si, en el momento de otorgar el testamento, la testadora, sin herederos legítimos, declara dejar todos sus bienes muebles, inmuebles, joyas, dinero o cualquier valor que pueda dejar a su fallecimiento, a $X$, fijando que este puede usar y alienar los bienes, pero agregando que los bienes que queden a su fallecimiento pertenecerán a $Y$, estará consagrando una sustitución fideicomisaria regular, un fideicomiso de residuo (art. 2295, $n^{\circ} 1$, b), del CC), en el que $X$ es fiduciario y $Y$ es fideicomisario, y no estará consagrando entonces a Y como heredero condicional, en los términos del artículo 2229 del CC.

II.- La facultad, referida por la testadora, de que $X$ pueda alienar los bienes que le ha dejado, no desacredita al fideicomiso de residuo, y por lo tanto el fiduciario no está exento, conforme a la ley, de obtener el consentimiento del fideicomisario para proceder a la venta de los biene.

Cunha Gonçalves (1946, p. 176) en la misma línea manifiesta que "el fiduciario que venda los bienes legados, sin obtener el previo consentimiento del fideicomisario, que es propietario condicional de estos, infringirá la ley y practicará una venta nula".

Por último, la autora Pimenta Coelho (2017, p. 1149) expresa al respecto que

En la línea b) del número 1 se prevé que el testador llame a alguien "a lo que quede de herencia" cuando el heredero muera. Puede parecer así que el heredero podría disponer libremente en vida de los bienes en causa, siendo por tanto atribuido al fideicomisario apenas aquello que eventualmente quedase en la fecha de la muerte del fiduciario. Sin embargo, y por fuerza en base a la parte final del n. ${ }^{\circ} 3$, el fiduciario en este caso sólo podrá alienar bienes entre vivos, y fuera de los casos previstos en el artículo $2291^{\circ}$, si obtiene la aprobación del fideicomisario, lo que limita sobremanera los poderes de disposición del fiduciario.

En definitiva, y llegados a este punto, podemos afirmar con rotundidad que el alcance de la sustitución fideicomisaria de residuo española sea mucho más amplia que la portuguesa, lo cual conlleva a que en España sea, en contradicción con su propio nombre, el tipo de sustitución fideicomisaria más usada en la práctica, mientras que en Portugal la institución hace honor a su nombre, teniendo un uso en la práctica totalmente residual, ya que apenas concede al fiduciario ninguna ventaja respecto a la sustitución fideicomisaria ordinaria, dado que éste para poder disponer de los bienes fideicomitidos necesitará el consentimiento del fideicomisario, lo cual, en la inmensa mayoría de las ocasiones, no llegaría a producirse.

\footnotetext{
I - Se, na ocasião da outorga do testamento, a testadora, sem herdeiros legitimários, aí declara deixar todos os seus bens móveis, imóveis, jóias, dinheiro ou quaisquer valores que possua à data do seu falecimento, a X, referindo a possibilidade de este usufruir e alienar os ditos bens, mas acrescenta que os bens que ficarem aquando do falecimento dele pertencerão a Y, consagra uma substituição fideicomissária irregular, um fideicomisso de resíduo ( $a \mathrm{rt}^{\circ} 225^{\circ}, \mathrm{n}^{\circ} 1, \mathrm{~b}$ ), do CC), em que X é fiduciário e Y é fideicomissário, e não a instituição de $Y$ como herdeiro condicional, nos termos no art. $^{\circ} 2229^{\circ}$ do CC. II - A faculdade, referida pela testadora, de X alienar bens assim deixados, não descaracteriza o fideicomisso de resíduo, não desonerando, por isso, o fiduciário de, em conformidade com a lei, obter o consentimento do fideicomissário para proceder à alienação de tais bens.
} 


\section{La sustitución fideicomisaria como institucion elegida en España para acabar con la intangibilidad de la legitima, a diferencia de lo que ocurre en Portugal}

En la legislación portuguesa (al igual que en la española) la legítima constituye una restricción a la libertad de disponer mortis causa, y se regula en el "Decreto-Lei № 47344 , de 25 de Novembro154 de 1966, Código Civil Português".

El concepto de legitima lo encontramos en la norma 2156 del Código Civil portugués, que la define como "aquella porción de bienes de la que el causante no podrá disponer por estar por ley destinada a los herederos legitimarios”.

Por tanto, en Portugal, como ocurría en España hasta 2003, el testador no podrá, bajo ningún concepto, disponer libremente de cierta parte de la herencia la cual está destinada a los legitimarios.

En España, ${ }^{10}$ en cambio, esto cambio en 2003, año en el que el legislador español aposto por la sustitución fideicomisaria como el instrumento jurídico a través del cual se permite vulnerar por primera vez ${ }^{11}$ el principio sagrado e histórico del Derecho Sucesorio de la intangibilidad de la legítima estricta, ya que desde la entrada en vigor de la Ley 41/2003 de Protección Patrimonial de las Personas con Discapacidad, en adelante LPPD, cualquier testador español con hijos o descendientes incapacitados judicialmente podrá establecer una sustitución fideicomisaria sobre todo el tercio de legítima estricta (hasta entonces, intocable), instituyendo como fiduciarios a los hijos o descendientes judicialmente incapacitados, y como fideicomisarios al resto de herederos forzosos, los cuales quedarán por ende gravados en su cuota de legítima estricta.

Es decir, tras la entrada en vigor de la LPPD los testadores españoles podrán beneficiar a sus hijos o descendientes incapacitados judicialmente no sólo con el tercio de libre disposición y el de mejora, más su cuota de legítima estricta, sino que también podrán establecer a su favor una sustitución fideicomisaria sobre todo el tercio de legítima estricta, vulnerando con ello la legítima estricta del resto de herederos forzosos, lo cual atenta contra todos los antecedentes históricos del C.c.

Por ello, en la actualidad en España los testadores con hijos o descendientes judicialmente incapacitados disponen de una mayor libertad de testar que los testadores que no tengan hijos o descendientes judicialmente incapacitados, ya que éstos últimos no pueden establecer la sustitución fideicomisaria sobre todo el tercio de legítima estricta a favor de sus hijos o descendientes no incapacitados, cosa que en cambio sí pueden hacer los primeros.

Para dar este nuevo alcance a la sustitución fideicomisaria el legislador de 2.003 modificó los artículos 782, 808 y 813.2 del C.c., los cuales, desde entonces, presentan el siguiente contenido:

Artículo 782 del C.c.:

Las sustituciones fideicomisarias nunca podrán gravar la legítima, salvo que graven la legítima estricta en beneficio de un hijo o descendiente judicialmente incapacitado en los términos establecidos en el artículo 808. Si recayera sobre el tercio de mejora, sólo podrán hacerse a favor de los descendientes.

Artículo 808, párrafo $3^{\circ}$, del C.c.: "Cuando alguno de los hijos o descendientes haya sido judicialmente incapacitado, el testador podrá establecer una sustitución fideicomisaria sobre el tercio de legítima estricta, siendo fiduciarios los hijos o descendientes judicialmente incapacitados y fideicomisarios los herederos forzosos".

Artículo 813 , párrafo $2^{\circ}$, del C.c.:

El testador no podrá privar a los herederos de su legítima sino en los casos expresamente determinados en la ley.

10 Tema al que le dedico el manual "La sustitución fideicomisaria especial introducida por la ley 41/2003: inicio de la tangibilidad de la legítima estricta y origen de la desigual libertad de testar existente en España”, Editorial Tirant Lo Blanch, 2.017.

1 Digo por primera vez, porque es una intangibilidad "real" de la legítima estricta la que permite la sustitución fideicomisaria en España, pudiendo llegar incluso a suponer, en nuestra opinión, la tangibilidad no sólo cualitativa, sino también, cuantitativa de la legítima estricta, por lo que nada tiene que ver con las excepciones a su intangibilidad cualitativa que existían con anterioridad a la entrada en vigor de la LPPD, excepciones que, por regla general, simplemente suponían el aplazamiento del cobro de la legítima, como era el caso de la cautela socini, o la posibilidad de conmutar la legítima en dinero. 
Tampoco podrá imponer sobre ella gravamen, ni condición, ni sustitución de ninguna especie, salvo lo dispuesto en cuanto al usufructo de viudo y lo establecido en el artículo 808 respecto de los hijos o descendientes judicialmente incapacitados.

Por todo ello podemos afirmar que en la actualidad en España la sustitución fideicomisaria parece ser una institución de más utilidad práctica que la institución portuguesa, ya que fue elegido en 2003 como el medio de protección de las personas incapacitadas por un lado, y como instrumento jurídico para vulnerar por primera vez el principio de la intangibilidad de la legítima estricta.

\section{Conclusiones}

Existen diversas importantes diferencias entre la sustitución fideicomisaria de España y la de Portugal, como por ejemplo, el hecho de que en Portugal el C.c. haga referencia a la institución como sustitución fideicomisaria o fideicomiso, cosa que en España no sucede, o que en Portugal solo se admita un llamamiento a favor de fideicomisarios, y en España se admitan dos llamamientos.

Pero en mi opinión, las diferencias más importantes desde el punto de vista práctico son dos:

1.- El alcance de la sustitución fideicomisaria de residuo portuguesa, en la que el fiduciario no podrá disponer de los bienes fideicomitidos sin autorización de los fideicomisarios, y el alcance de la de residuo española, en la que el fiduciario si podrá disponer libremente de los bienes fideicomitidos, siendo el testador el único que puede imponer ciertos límites en tal sentido, pero nunca deberá el fiduciario pedir autorización al fideicomisario para disponer de los bienes fideicomitidos.

2.- El nuevo alcance que se le otorgo en 2003 a la sustitución fideicomisaria española, y que no ocurre en Portugal, como es el hecho de que a partir de entonces los testadores españoles con hijos o descendientes judicialmente incapacitados pueden establecer a su favor una sustitución fideicomisaria sobre todo el tercio de legitima estricta a favor de estos, los cuales pasan a convertirse en fiduciario, siendo por tanto fideicomisarios el resto de herederos forzosos.

O lo que es lo mismo, en España la sustitución fideicomisaria ha sido elegido como el instrumento jurídico a través del cual vulnerar por primera vez el principio histórico de la intangibilidad de la legítima, situación que, en cambio, no se ha dado en Portugal.

\section{Bibliografía}

AGUIAR BRANCO, Fernando. Dos Fideicomissos. Porto: Fundação Eng. António de Almeida, 2000. BOTELLO HERMOSA, P. El incomprensible uso como sinónimos de dos figuras jurídicas diferentes: el fideicomiso y la sustitución fideicomisaria. Revista Critica de Derecho Inmobiliario, Madrid, Año 92, n. 756, p. 2264-2280, 2016.

BOTELLO HERMOSA, P. La sustitución fideicomisaria especial introducida por la ley 41/2003: inicio de la tangibilidad de la legítima estricta y origen de la desigual libertad de testar existente en España. Valencia: Editorial Tirant Lo Blanch, 2017.

CASTÁN, José. Derecho civil español, común y foral. Madrid: Instituto Editorial Reus, 1942. t. 4.

COSTA, Joaquín. Fideicomisos y Albaceazgos de confianza y sus relaciones con el Código Civil Español. Madrid: Editorial Marcial Pons, 1905.

CUNHA GONÇALVES, Luis da. Fideicommisso de Residuo. Revista da Ordem dos Advogados, Lisboa, v. 1, ano 6, n. 1 e 2, p. 176-180, 1946.

DE ABREU LIMA, João G. Substituição Fideicomissária. 1950. Dissertação (Licenciatura em Ciências Jurídicas) - Faculdade de Direito da Universidade de Coimbra, Coimbra, 1950.

DE BUEN, Demófilo, en sus notas a COLIN y CAPITANT. Curso elemental de Derecho Civil. Madrid: Editorial Reus, 1975. t. 8 
DÍAZ ALABART, S. El fideicomiso de residuo: su condicionalidad y límites. Barcelona: Editorial Bosch, 1981.

DÍEZ-PICAZO, Luis; GULLÓN, Antonio. Sistema de derecho civil, derecho de sucesiones. 11. ed. Madrid: Editorial Tecnos, Madrid, 2012. v. 9.

LÓPEZ Jerónimo. La regulación del fideicomiso de residuo en el Código civil español. Anuario de Derecho Civil. 1955.

LASARTE, Carlos. Derecho de Sucesiones. Principios de Derecho Civil VII. 7. ed. Madrid: Editorial Marcial Pons, 2011.

NIETO ALONSO, Antonia. Sustitución fideicomisaria de residuo, usufructo testamentario de disposición y donación: la atribución de facultades dispositivas y la repercusión de la situación de necesidad. Madrid: Editorial Wolters Kluwer, 2014.

OSSORIO MORALES, Juan. Manual de sucesión testada. Madrid: Instituto de Estudios Políticos: Madrid, 1957.

PIMENTA COELHO, Cristina. Substituição Fideicomissária. En: PRATA, Ana (coord.). Código Civil Anotado. Lisboa: Editorial Almedina SA, 2017. v. 2. p. 1166-1174.

PUIG BRUTAU, José. Fundamentos de derecho civil. 2. ed. Barcelona: Editorial Bosch, 1977. t. 5. v. 2. PUIG FERRIOL, Lluis. EI heredero fiduciario. Barcelona: Publicaciones de la Cátedra de Derecho Civil "Durán y Bas", 1965.

RIVAS MARTÍNEZ, Juan José. Problemas "habituales" en los testamentos y particiones con los fideicomisos normales y de residuo. In: YAGÜE, Lledó; VANRELL, Ferrer; LANA, Torres (dir.). EI patrimonio sucesorio: Reflexiones para un debate reformista. Madrid: Editorial Dykinson, 2014. t. 1.

SÁNCHEZ ROMÁN, Felipe. Estudios de derecho civil: derecho de sucesiones. Madrid: Impresores de la Real Casa, 1910. t. 6.

SANTOS JUSTO, Antonio dos. Direito Privado Romano - V (Direito das Sucessões e Doações). Boletim da Faculdade de Direito. Coimbra: Coimbra Editora, 2009. v. 5.

SOLÉ RESINA, Judith. Sustitución fideicomisaria en el Código Civil. En: GETE-ALONSO Y CALERA, Ma. Del Carmen (directora). Tratado de Derecho de Sucesiones. Navarra: Editorial Aranzadi, 2011. t. 1. p. 871-896.

TRAVIESAS, M. Sustituciones Hereditarias. Revista de Derecho Privado, Oviedoia, v. 28, n. 171, 15 dic. 1927.

Recebido em: 08/07/2020

Aprovado em: 03/09/2020 